\title{
La fuga de Edipo. El pliegue Deleuze-Lacan
}

Ani Bustamante

Nueva Escuela Lacaniana

Resumen: Este artículo pretende poner en tensión las posiciones de Deleuze y Lacan en relación a las teorizaciones relacionadas a la idea del complejo de Edipo heredero del psicoanálisis freudiano. Esta tensión se expresará al revisar los conceptos de deseo, represión y castración, desde el punto de vista de la relación del sujeto con el lenguaje. Para esto atravesaremos por las propuestas topológicas gracias a las cuales, tanto Deleuze como Lacan, pueden dar cuenta de aquello que se aloja por fuera de la lógica significante, cuyo eje paradigmático es justamente la lógica edípica, para así llegar a forjar un trabajo de frontera en el cual la materialidad del lenguaje, su sonoridad y textura cobraran relevancia para repensar el estatuto mismo del inconsciente.

Palabras clave: psicoanálisis, Edipo, deseo, inconsciente.

Abstract: This article aims to put face to face the positions of Deleuze and Lacan in relation to the theories regarding the idea of the Oedipus complex inherited from Freudian psychoanalysis. This confrontation will become manifest by reviewing the concepts of desire, repression and castration, from the point of view of the subject's relationship with language. In order to achieve this purpose, we will go through the topological proposals whereby both Deleuze and Lacan render account of that which is housed outside the signifying logic, the paradigmatic axis of which is precisely the Oedipal Logic, thus forging a cutting-edge work in which the materiality of language, its sonority and texture will acquire relevance to rethink the status of the unconscious itself.

Keywords: psychoanalysis, Oedipus, desire, unconscious. 


\section{$\S 1$. Fuga}

Trazar algunas líneas entre Deleuze y Lacan implica transitar por un campo de atonalidades para poner en marcha un pensamiento que podríamos ubicar en la dimensión de una cierta lógica musical. Así tenemos, pues, filosofía y música trabajando en los márgenes de la representación. En este trabajo propondré que hay algo en el tono de ambos pensadores, relacionado al trabajo con el lenguaje, que resuena en el cuerpo y que puede ser vertebrado a través de la sonoridad de la lengua.

Haré pues una fuga que me permita entrecruzar, como quien teje con hilos de diversas texturas, colores y grosores, sin reducir las líneas teóricas que trabajaremos a un solo cuerpo homologado. Es en este entramado polifónico en el que la fuga es posible, entre sus pliegues barrocos y la multiplicidad de notas que encuentra su diferencia, en la repetición misma. Tenemos, pues, líneas de fuga freudianas, lacanianas, deleuzianas, para componer con ellas algo, y producir un nuevo agenciamiento que implique no edipizar el pensamiento, y trabajar a modo "ritornelo", producir territorializaciones, desterritorializaciones y reterritorializaciones, como ciclos productivos de vida.

\section{§ 2. Deleuze y el psicoanálisis}

Se ha dicho mucho sobre la relación ambivalente de Deleuze con el psicoanálisis, desde su importante influencia y concordancia de los inicios, hasta la confrontación y discordancia del último tiempo con Guattari. Es importante no obviar ese recorrido y situarlo en su contexto, pues ni Deleuze fue tan ingenuo como para creer que el psicoanálisis era la parodia que describe en El anti-Edipo, ni Lacan tan despistado como para no valerse de la potencia del pensamiento de Deleuze-Guattari, para pensar el posible recorrido de un análisis que pueda ubicarse de otra manera frente a la figura del padre y los avatares del imaginario edipico.

En primera instancia quisiera comentar que lo que me parece un punto fundamental en ambos autores es su construcción de modelos espaciales, a partir de los cuales pensar un inconsciente superficial. Así, tenemos planos

I62 de inmanencia en Deleuze y nudos en Lacan; todo esto es el resultado de 
una búsqueda por descolocar el pensamiento de su eje, para lanzarlo hacia aquello que no puede ser domesticado por el significante.

Es evidente que ambos autores deconstruyen ese Edipo que, bien dice Lacan, fue el sueño de Freud, orientado a la búsqueda de una verdad última. En ese sentido el Edipo freudiano es aquel que llega hasta las últimas consecuencias con tal de "develar" la verdad de la esfinge. "La novela de Freud son sus amores con la verdad"', dice Lacan. Con Freud tenemos una primera línea, vertical, arqueológica, que propone profundidades para llegar al inconsciente, que será, como lo llama Deleuze, un inconsciente representacional, teatral.

Detrás de la escena, Freud dirige los signos, pretende un significado, busca la verdad, sabiendo que, frente a ese límite navegará entre significantes, que solo llevarán a otros significantes (siendo el sujeto, efecto de esta operación). Tenemos entonces, por un lado, esta arqueología freudiana, cuya ancla teórica es el complejo de Edipo, que da lugar a la estructuración de la prohibición relacionada al incesto, el deseo y la ley.

El paradigma freudiano, a partir de la histeria, esta pues fundado en la idea de represión y en la clínica de la neurosis (a diferencia de Lacan que parte de la psicosis). Para Deleuze, el deseo freudiano, sostenido en el Edipo, sedentariza al sujeto. Dice en Lógica del sentido: "Un psicoanálisis debe hacerse sobre dimensiones geométricas, antes que sobre anécdotas históricas. Porque la vida, la sexualidad incluso, están en la organización y la orientación de estas dimensiones, antes de ser materias generadoras y formas engendradas. El psicoanálisis no puede contentarse con designar casos, manifestar historias o significar complejos. El psicoanálisis es psicoanálisis del sentido (con Lacan). Es geográfico antes de ser histórico"2.

Este modo de plantear lo inconsciente en Deleuze se relaciona con la última enseñanza de Lacan, ambos buscan franquear la barrera de la significación para ir hacia aquello que se resiste a ser modificado a partir de lo simbólico, aquello que está por fuera de la representación en el territorio de lo impensable. Para Lacan será un trabajo sobre la pulsión y el goce, mientras que para Deleuze

I Lacan, Jacques, “Nota italiana”, en: Otros escritos, Buenos Aires: Paidós, 2012, p. 329.

2 Deleuze, Gilles, Lógica del sentido, Barcelona: Paidós, 1994, p. 109. 
será sobre flujos de deseo y líneas de fuga que transitan rizomaticamente en un plano de inmanencia. Tanto Deleuze como el último Lacan rompen con la interpretación freudiana tradicional, postulando un inconsciente superficial a producir.

Mientras la interpretación clásica está relacionada a la arqueología, a un modelo de inconsciente a descubrir o decodificar; el esquizoanálisis deleuziano se desplaza en un plano horizontal que no busca traducir ni interpretar, sino más bien generar líneas de fuga rizomáticas (el inconsciente como máquina de producción). Estas líneas de fuga se trabajan en la clínica lacaniana a partir de las escansiones que operan a la manera de un poema, con los decires de un sujeto.

\section{$\S 3$. El plano y sus pliegues}

Con un inconsciente superficial, ya no se apela a la profundidad en la que reside la verdad, sino más bien, se toman en cuenta los movimientos de superficie, para en ellos recorrer los pliegues formados. Dice Deleuze en El pliegue: “Lo múltiple no sólo es lo que tiene muchas partes, sino lo que está plegado de muchas maneras"3.

Situar, entonces, al inconsciente en una superficie, nos permite pensar lo íntimo como un pliegue mismo del afuera. Con el pliegue entendemos el adentro y el afuera sin necesidad de recurrir a honduras, ni trascendencias, nos permite poder darle un lugar a lo interior, sin hacer de ello un compartimento separado o profundo, sino aquello que aparece justo en el lugar del plegamiento, que, con el movimiento propio de las fuerzas que habitan al sujeto deseante, pasará por desplegamientos que evidenciaran el carácter de superficie de ese interior. Digamos que aquí Deleuze hace una suerte de operación que, lacanianamente

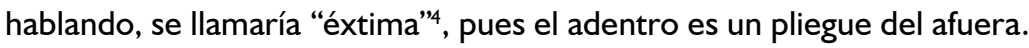

3 Deleuze, Gilles, El pliegue, Barcelona: Paidós, 1989, p. II.

4 Lacan inventa el neologismo "extimidad" para dar cuenta de cómo lo más íntimo de un sujeto deviene exterior, problematizando así los conceptos de interior-exterior. 


\section{$\S 4$. De la estructura a la textura}

Cuando Deleuze y Guattari elaboran El anti-Edipo, las críticas se dirigirán, entre otras cosas, al estructuralismo y la idea del inconsciente estructurado como un lenguaje. Dice Deleuze que el estructuralismo es "un sistema de puntos y posiciones, que en lugar de proceder por estallidos y crecimientos actúa por grandes cortes significantes y obstruye las líneas de fuga en lugar de continuarlas, destrazarlas, en el campo social"5. De lo que se trata, pues, es de no interrumpir el estallido para así poder ir a la búsqueda de lo que todavía no ha sido pensado y que no es imitación ni representación de algo anterior.

Deleuze piensa de muchas maneras las alternativas al estructuralismo y al modelo inconsciente del freudismo; es interesante como, por ejemplo, el modelo del pliegue trae una serie de metáforas que van llevando a proponer una relación fundamental entre filosofía y arte. A partir del uso de la palabra «textura» en Leibniz encontramos una formulación que plantea este tejido, que llama al tacto y a los sentidos, como salida del estructuralismo. Deleuze se desliza de la estructura a la textura y propone una estética de las texturas ${ }^{6}$ : "La superficie, la cortina, la alfombra, el manto, ahí es donde el cínico y el estoico se instalan y con lo que se envuelven. El doble sentido de la superficie, la continuidad del derecho y el revés, sustituyen a la altura y la profundidad"7.

Este es un giro importantísimo que coloca a Deleuze como un filósofo fronterizo que lleva las palabras hasta el umbral del cuerpo, en donde ya no se trata de ver qué pasa con la significación, pues la operación es sobre la pura materialidad del lenguaje en tanto artefacto productor de conexiones. Deleuze rompe el molde de las formas fijas y de las identidades iguales a sí mismas, para poner en marcha las paradojas del interior/exterior, ser/no-ser a través de sus plegamientos/desplegamientos.

Todo sube a la superficie, todo se juega en la piel y sus transformaciones temporales. Reversibilidad de las posiciones del adentro y del afuera, de lo

5 Deleuze, Gilles y Claire Parnet, Diálogos, Valencia: Pretextos, 1980, p. 46.

6 Cf. Deleuze,Gilles, “Les Cours de Gilles Deleuze (19/05/1987)", en: Webdeleuze (www. webdeleuze.com).

7 Deleuze Gilles, Lógica del sentido, p. 144. 
material y de lo inmaterial, del yo y del otro: "Es siguiendo la frontera, costeando la superficie, como se pasa de los cuerpos a lo incorporal" ${ }^{\circ}$; esta idea de continuidad sustituye a todos los niveles de profundidad.

Por otro lado Lacan, al inicio de su obra, hizo una lectura estructuralista de Freud, logrando con esto desustancializar la idea de sujeto, para dejarlo como un lugar vacío, inestable y sin identidad a priori. Fue el primado de lo simbólico en la teoría lacaniana, la apuesta por el significante, su cadena y articulaciones. Este Lacan estructuralista siguió un recorrido, orientado por la clínica de las psicosis, y por un cuestionamiento cada vez mayor al lenguaje representacional y sus incidencias en la cura a través de la interpretación. Con esto termina de liberar a Edipo de las codificaciones de la "casa familiar", la "casa de la cadena significante", y el sujeto que ésta produce. Por otro lado, en la medida en que va articulando una lógica que "no pasa toda" por el significante y su cadena, Lacan irá dejando de hablar en términos de sujeto (ya que éste es producto de la operación significante y corresponde al paradigma del inconsciente estructurado como un lenguaje) para poner el acento en el ser, en el ser hablante.

Es este último Lacan el que sale de las estructuras hacia las texturas, el que hace figuras de cordel, trabajos manuales, el que toca la letra para escuchar su resonancia en el cuerpo; es el que, a mi modo de ver, puede pensarse con Deleuze. Sin hacer analogías reductoras, manteniendo la polifonía, estas dos voces se cruzan, de tal manera que podemos ubicar a un Lacan proponiendo que hay un cuerpo de goce (al que se accede en un trabajo sobre la letra inscripta como pura cifra por fuera de la significación) y un Deleuze que produce un cuerpo conceptual sostenido en la idea de Maquinas deseantes.

Lacan propone un lugar de borde, donde la palabra no llega a significar claramente la experiencia $y$, en esa frontera con lo innombrable echa mano de la topología para mostrar aquello que no puede ser nombrado. Al tomar distancia de la construcción mítica del complejo de Edipo freudiano, Lacan propone un “más allá de Edipo". Sin embargo, aunque nunca habló en términos de complejo de Edipo, si lo hizo en términos de "castración" y "nombre del padre", este 
último irá sufriendo variaciones, hasta llegar a la lógica borromea' ${ }^{9}$ con lo cual es el nudo el que cumple la función otorgada a la paterna, y serán las formas de anudamiento las que determinaran la clínica de cada sujeto.

Con los nudos, Lacan irá priorizando el registro de lo real, es decir, de lo irrepresentable que se imprime como marca y sonido en el cuerpo. Esta maniobra la hará a partir de lo que llamará "la letra" (pura marca que no se introduce en la lógica de la significación), y "la lengua" (el lenguaje en tanto sonoridad por fuera del sentido). Los esfuerzos de Deleuze, y también de Lacan, por resituar el deseo, toman caminos que se bifurcan, se cruzan, desentonan y que, sin embargo, nutren el ritmo de pensamientos que no cesan de buscar una otra manera de nombrar las fuerzas vitales que recorren el cuerpo.

Fuerzas pulsionales bordeando lo imposible, el agujero del lenguaje, en Lacan. En Deleuze, maquinas deseantes en cuya lógica el deseo no está atravesado por ningún imposible. Pura potencia afirmativa. Deleuze cuestiona a Lacan que no haya eliminado por completo la negatividad del deseo, manteniendo la operación de castración como eje de sus formulaciones. Es este un punto de fractura entre ambos, pues mientras Lacan mantiene una ontología negativa, y articula la pulsión de muerte a la idea de repetición, para Deleuze la repetición funciona como un "ímpetu vital".

Sin embargo, la arremetida, a veces caricaturesca, de Deleuze a Lacan, no es tal si, siguiendo a Zizek pensamos en: "el reverso del edipo lacaniano como una suerte de 'precursor oscuro' de Deleuze que media entre las dos series: el relato edípico 'oficial normalizado', por una parte, y el campo presubjetivo de intensidades y máquinas deseantes, por otra"'10.

La esquizofrenia propuesta por El anti-Edipo no debe ser entendida como una reducción clínica, sino más bien como un proceso de apertura que camina de la mano del deseo. Es por esto que puede ser interesante pensar una posible salida del laberinto neurótico a través del paradigma esquizo, que se agencia en un plano de inmanencia, sin jerarquías. Con la esquizofrenia el inconsciente

9 La lógica borromea se establece a partir de la articulación en el nudo borromeo de los registros simbólico-imaginario-real.

10 Zizek, Slavoj, Órganos sin cuerpo, Valencia: Pre-Textos, 2006, pp. 100-101. 
aparece "a cielo abierto" en toda su desnudez: "Los esquizos nos enseñan que el deseo es producción y conexión de órganos, flujo, unión y corte de flujo"|l.

\section{$\S 5$. En el pliegue}

Hay un contrapunto entre Deleuze y Lacan, un cruce a través del acercamiento a la literatura y al estudio de aquellos escritores que exploraron la lengua en tanto aparato fonador, sonoro, maquínico. Deleuze, trabajará a partir de Proust y de Artaud. Lacan lo hará a partir de Joyce.

Ambos hacen un pliegue y se encuentran al proponer un tratamiento fragmentario del lenguaje, de tal manera que la articulación de la cadena significante estalle. La literatura deleuziana surge a partir de "la maquina literaria" que nada tiene que ver con el sentido y se aleja de la "narrativa del yo" y sus historias. Lo que importa es que la maquina literaria nómade funcioné, produzca cosas, se conecte con otras máquinas. Para Deleuze, la obra de Proust representa esa máquina en la que las partes son producidas como objetos fragmentados: "Proust decía que el todo es producido, que es producido como una parte al lado de las partes, que ni unifica ni totaliza, sino que se aplica a ellas instaurando solamente comunicaciones aberrantes entre vasos no comunicantes, unidades transversales entre elementos que mantienen toda su diferencia en sus propias dimensiones"'2.

Vemos pues que ambas propuestas se sostienen en la psicosis. Efectivamente, así como para Deleuze la maquina literaria es psicótica, para Lacan la lógica nodal adquiere toda su fuerza a partir Joyce, quien le servirá de apoyo para entender la manera de organización y funcionamiento en las psicosis.

El último lacan parte de la locura y del presupuesto: "estamos todos locos". Esta es pues una apuesta por la singularidad, y por la ruptura de las clasificaciones y los estándares neuróticos. Estar loco implica que cada uno tiene una manera de anudar-se absolutamente propia.

II Mengue, Philippe, Deleuze o el sistema de lo múltiple, Buenos Aires: La Cuarenta, 2008, p. 274.

12 Deleuze, Gilles y Felix Guattari, El ant-iEdipo, Barcelona: Paidós, 1998, p. 48. 
Hasta estos confines llegó la función paterna en Lacan; así pues, ya no se trata de un padre nominador, se trata de un saber-hacer con el síntoma. Cada cual tejiendo su nudo. Cada cual ante la necesidad de inventar una ruta no "normalizada". En todo caso, este último Lacan dirige una clínica por fuera del sentido, un manejo de las palabras del otro a partir de su sonoridad. Dice sobre esto que: "Las pulsiones son el eco en el cuerpo del hecho de que hay un decir"'3.

Por lo tanto, lo que interesa de Joyce es su trabajo sobre la letra que apunta a la extinción del lenguaje en tanto que significativo, a través de enigmas, polisemias y trasliteraciones para explotar al máximo las posibilidades fonéticas a costa de la destrucción de la lengua inglesa.

Tanto Deleuze como Lacan llevan su itinerario hacia un trabajo sobre la escritura, la esquizofrenia y los límites de la representación, ambos producen una escritura tan inquietante como gozosa, una escritura que va agujereando el despotismo totalizante de la razón. Escritura en acto, como maquina misma de producción de flujos y cortes, en el caso Deleuze; y de agujeros y tratamiento del goce en Lacan. En ambos casos es el sonido el que permite este tratamiento de lo real del cuerpo en su vínculo con el sexo y la muerte.

\section{§ 6. Sonido}

En relación al sonido, también en Mil Mesetas, Deleuze y Guattari dicen que: "No se mueve a un pueblo con colores. Las banderas nada pueden sin las trompetas" 14 . El sonido ofrece de manera directa los movimientos del ritornelo, y el ritornelo es lo que hace posible agenciar un territorio que luego pueda generar las condiciones para su desterritorialización, es decir, construye la casa y la salida al cosmos.

En este sentido, el "niño deleuziano” no está regido por Edipo, sino quizá por ritornelo: "Un niño en la oscuridad, presa del miedo, se tranquiliza canturreando. Camina, camina y se para de acuerdo con su canción. Perdido, se cobija

13 Lacan, Jacques, Seminario 23: el sinthome, Buenos Aires: Paidós, 2006, p. 18.

14 Deleuze, Gilles y Guattari, Felix, Mil Mesetas: capitalismo y esquizofrenia, Valencia: PreTextos, 2004, p. 35I. 
como puede o se orienta a duras penas con su cancioncilla. Esa cancioncilla es como el esbozo de un centro estable y tranquilo, estabilizante y tranquilizante, en el seno del caos"15.

Luego, Deleuze nos mostrará el movimiento del ritornelo en la casa y en el cosmos. Es decir, el canturreo del niño va sirviendo de hilo para pasar de un territorio a otro. "Fuerzas del caos, fuerzas terrestres, fuerzas cósmicas: las tres se enfrentan y coinciden en el ritornelo"16.

Deleuze busca un discurso que se podría asimilar a la música atonal coexistiendo con el espíritu del barroco, y así como la música atonal se despliega siguiendo formas diferentes a las de la música tradicional, sin dejar por ello de ser música, el pensamiento de Deleuze rompe con la dictadura de los significantes representativos sin que se desvanezcan los conceptos filosóficos.

A mi modo de ver, el poema es el que lleva las líneas del sonido, ritmo y letra hasta su máxima expresión. Tocando el cuerpo sin necesitar razones que se alcen hegemónicas. Quizá, entonces, el poema sea un pliegue posible situado en una zona intermedia, en un "intermezzo" entre Deleuze y Lacan. 